\title{
Gaps in Flood Disaster Management in India
}

\author{
L. $\operatorname{Arun}^{1 *}$ and R. Senthilkumar ${ }^{2}$ \\ ${ }^{1}$ Department of Veterinary and Animal Husbandry Extension, CVAS, Mannuthy, Kerala, India \\ ${ }^{2}$ MSRS, Pottaneri, Tamil Nadu, India \\ *Corresponding author
}

\section{A B S T R A C T}

\begin{tabular}{|l|}
\hline Ke y w o r d s \\
$\begin{array}{l}\text { Flood disaster, } \\
\text { Gaps, Disaster risk } \\
\text { reduction }\end{array}$ \\
\hline Article Info \\
\hline $\begin{array}{l}\text { Accepted: } \\
\text { 04 December } 2020 \\
\text { Available Online: } \\
\text { 10 January } 2021\end{array}$ \\
\hline
\end{tabular}

Flood has been considered as one of the most recurring and frequent disasters in the world. Due to recurrent prevalence, the economic loss and life damage caused by the flood has put more burdens on economy than any other natural disaster. India has continuously suffered by many flood events which claimed huge loss of life and economy. It has been found that the incidences of the flood are increasing very rapidly. The damage caused by flood lasts several years from its advent. Traditionally flood management strategies in India in almost all states have been geared towards 'preventing' flood which means taming the flow of water by containing flood water. This 'reactive' approach adopted by both central and state government has proven to be utter failure as the history of flood management is concerned. There exist many gaps in management of flood disaster in India. Gaps exists mainly in non-availability of close contour maps and digital elevation models of flood prone areas, lack of flood forecasting and warning network in all the flood prone rivers and rivulets, lack of advance technologies in flood forecasting and warning network, lack of advanced system of hazard communication, enactment and enforcement of flood plain zoning regulations and lack of inflow forecasting systems for the reservoirs. In order to plug the gaps in flood disaster management a comprehensive hazard, vulnerability and risk assessment and communication need to be put up in place along with enhanced investment on research and development related to disaster resilient technology and improvising traditional disaster risk reduction practices.

\section{Introduction}

India is one of the most flood-prone countries in the world after Bangladesh. Since the National Flood Control Program launched in 1954, sizeable progress has been made in structural and non-structural flood protection measures. Structural measures involve the construction of physical structures like embankments, dams, drainage channels, and reservoirs that prevent flood waters from reaching potential damage centres, whereas non-structural measures like flood forecasting aim at improving the preparedness to floods by keeping people away from flood waters (Singh and Kumar, 2017).

Traditionally flood management strategies in India in almost all states have been geared towards 'preventing' flood which means 
taming the flow of water by containing flood water. This 'reactive' approach adopted by both central and state government has proven to be utter failure as the history of flood management is concerned.

\section{Gaps in flood disaster management}

Non-availability of close contour maps and digital elevation models of flood prone areas

Mapping flood hazard is most important endeavour to be taken up by in any country affected by flood. A risk map is a special topographic map where the hypothetical flood characteristics are represented graphically. It is convenient for singling out a special test flood risk mapping, because a flood map synthesizes past flood events. If such flood events are recorded sufficiently and accurately to enable the drawing of flooding contours, the empirical value of the results is highly important. Risk mapping is the basic tool and starting point of any regional intervention policy for flood control. A flood risk map is considered as a preliminary yet necessary initial step for all regional development policies (Marco, 1994).

But the scheme of flood hazard mapping does not paint a rosy picture in Indian perspective. Very little attention is being paid on formulating rational land use planning to reduce flood induced disaster. Preparation of a comprehensive flood hazard map for all the states would be one of most crucial steps for implementing non-structural flood remedial measures.

Incorporation of those resources would definitely enhance accuracy of the analysis. In the current state of technology and resources possessed by India, preparation of proper kind of hazard maps is not feasible (Sanyal and Lu, 2003).
But, presently with co-operation from ISRO flood hazard mapping for India is fast paced. Satellites, by virtue of their remote sensing and data transmission capabilities, provide comprehensive multi-date and multi-spectral information on dynamic phenomena covering very large as well as small river basins. The data provided by satellites have been found to be admirably suited for mapping/monitoring and studying the following parameters,

Flood inundated and drainage congested areas,

Extent of damages to crops, structures, River configuration, silt deposits, shoals and vulnerable areas of bank erosion

Watershed characteristics and land cover/land use in command areas and

Hydrological and meteorological data transmission from data collection platforms.

The flooded areas, which extend to several thousands of square kilometres, could be mapped very effectively using the satellite data. They are also useful in delineating the boundaries of flood prone zones. Digital analysis of satellite data can detect changes on the sections of the inundated flood plains as well as in water quality. The multi temporal data from satellites are proved to be very valuable in the identification of the site ideal for taking up structural measures to control floods (Gangwar, 2013).

\section{Need of flood hazard mapping}

If the inundation maps could be prepared, there will be less mismanagement in relief administration and the chances of corruption also will reduce. The Community based Organisations, the Non-Governmental Organisations and common people can make use of the information as the inundation maps can be used by anybody. The task may be easier in the states where the Panchayati raj institution exists and the participation of such 
institutions will be ensured in the management of the crisis. When the flood waters strike without much of prior information then the first thing that a householder has to do is to move his family and the cattle to some safer place and then arrange immediately the essential commodities like food and some roofing cover. Food will be needed immediately and within hours of shifting, protection against rains will be ensured (Mishra, 2001).

The process involved in preparation of close contour maps and digital elevation models is so vast and complicated that the only institution which is capable of preparing it is the government, as no other agency has the resources, human power, information or the expertise to carry out the job. The government's role in coordinating and preparing flood hazard maps can hardly be emphasised because not only it possesses the information; it possesses the authority too. The Central and state governments need to address this issue and fill up this gap.

\section{Lack of flood forecasting and warning network in all the flood prone rivers and rivulets}

The science and technology of flood disaster mitigation addresses policy, planning, design, and operational aspects. Good policy and planning can reduce the exposure to flooding through control of land management and housing development whilst well designed flood defence schemes will alleviate the impact of flooding. However, complete protection from flooding is rarely a viable goal. Provision of flood forecasting and warning systems can bring significant benefits through giving forewarning of imminent flooding, allowing timely evacuation, relocation of valuables, and management of affected infrastructure. Effective mechanisms of dissemination and human response are required to ensure that the potential benefits of forewarning are realised (Werner et al., 2005).

The purpose of a national flood forecasting and warning system is to provide as much advance notice as possible of an impending flood to the authorities and the general public. Over time, the demands for flood forecasts evolve from a general indication of the likelihood of flooding, for example, on major rivers to a more definitive prediction of magnitude and timing at key locations. The main components of a national flood forecasting and warning system are the following:

(a) Collection of real-time data for the prediction of flood severity, including time of onset and extent and magnitude of flooding;

(b) Preparation of forecast information and warning messages, giving clear statements on what is happening, forecasts of what may happen and expected impact;

(c) Communication and dissemination of such messages, which can also include what action should be taken;

(d) Interpretation of the forecast and flood observations, in order to provide situation updates to determine possible impacts on communities and infrastructure;

(e) Response to the warnings by the agencies and communities involved;

(f) Review of the warning system and improvements to the system after flood events (WMO, 2011).

In India, the difficulties in estimating (and observing) rainfall continuously over space have constrained the advances in flood forecasting and warning. While weather radar 
in combination with rain gauge observations has offered the prospect of progress, there have been significant concerns to be overcome (Roy et al., 2019).

Flood forecasting and warning systems in integration with the rainfall monitoring and forecasting are currently adopted in many countries across the globe. In India, despite the substantial technical progress, several challenges from an operational point of view need to be addressed for successful implementation of such a system. Challenges in particular include communicating risk information and early warnings to the responder agencies (disaster management agencies) and to the population at-risk (Cools et al., 2016). In addition, these agencies or the population at-risk should also be trained to respond to these warnings and trigger an appropriate response action.

\section{Lack of advanced technologies in flood forecasting and warning network}

In India, most of the techniques for formulating the real time flood forecast are based on statistical approach. For some pilot projects, network model and multi parameter hydrological models are used. Conventional systems of communication are normally used for transmitting the data in real time.

The automatic systems of data communication like Telemetry system are used in pilot projects on limited scale. The lack of advanced system of flood forecasting and warning results in heavy losses of lives and properties.

There is a need for significant improvement of the real time flood forecasting systems in India. Efficient automatic communication systems are required to be established for transmitting the data in real time (Wheater et al., 2007).
Central Water Commission (CWC) undertook the work of modernization of flood forecasting network during the IX Plan on pilot basis. The modernization works envisaged establishment of telemetry equipment in the Flood Forecasting System (FFS) to enable collection and transmission of automatic real time data, automatic formulation of flood forecast and expeditious dissemination thereof in order to increase the lead time for enabling concerned agencies to undertake mitigation measures for reducing the risk of disasters from flood. Against a target for the XII Plan for installation of 219 telemetry stations, 310 base stations and 100 flood forecasting stations, only 56 telemetry stations had been installed as of August 2016. Most of the telemetry stations installed during XI plan were non-functional due to which real time data was not available at these stations. Therefore, CWC did not depend on telemetry data even after investing in modernisation of telemetry station network for nearly 20 years which defeated the purpose of establishment of telemetry stations. There were insufficient numbers of flood forecasting stations in some of the States [Report (1), 2007].

To form an effective real-time flood forecasting system, the basic structures need to be linked in an organized manner. This essentially requires:

(a) Provision of specific forecasts relating to rainfall for both quantity and timing, for which numerical weather-prediction models are necessary;

(b) Establishment of a network of manual or automatic hydrometric stations, linked to a central control by telemetry;

(c) Flood forecasting model software, linked to the observing network and operating in real time (WMO, 2011). 
Lack of advanced system of flood disaster risk communication

Risk communication is central to international disaster risk reduction strategies because preparedness and response measures depend not simply on the soundness of the underlying scientific risk assessments but also on the effectiveness with which that information is conveyed to those responsible for acting on it. (Asian, 2002).Given the potential for errors in any scientifically driven product, it is now increasingly recognized that communicating the uncertainty associated with scientific forecasts is as important for risk management as increasing their accuracy and timeliness. (National Research Council, 2006)

Flood forecasting and advance warning for 148 low-lying areas and towns and 28 reservoirs help other government agencies with decision making to implement flood mitigation measures, such as the evacuation of residents and shifting their movable property to safer locations. Inflow forecasts at 28 reservoirs are used by dam authorities to manage reservoir gate operation for the release of discharges downstream. Reservoir inflow forecasts are also used to ensure adequate storage in the reservoirs to meet irrigation and hydropower generation demands during non-monsoonal periods. Such services are available annually during the flood period, from May through December. The forecast is disseminated using a range of communication pathways, such as fax, wireless, phone, mob, SMS, email, electronic media, print media, social media, website, etc. Annually, over 6000 flood forecasts and advance warnings are issued by CWC regional offices across the country to government agencies during floods. (Adams III, 2019)

Efficient automatic communication systems are required to be established for transmitting the data in real time. The forecasting techniques such as deterministic models, stochastic models, ANN and Fuzzy Logic techniques are required to be studied and a suitable method may be recommended for field applications based on the performance evaluation criteria and considering the data availability and purpose of the forecast. The information about the flood has to be disseminated well in advance to the people likely to be affected so that an emergency evacuation plan may be prepared and properly implemented (Wheater et al., 2007)

\section{Enactment and enforcement of flood plain zoning regulations}

Floodplain zoning means restricting any human activity in the flood plains of a river where the plains are created by overflow of water from the channels of rivers and streams. Generally the term flood plain includes the water channel, flood channel and area of nearby low land susceptible to flooding by inundation.

The activity of flood plain zoning has the short term objective of preventing more damage from flooding and in the long term to reduce and even eliminate such damage. Flood Plain Zoning aims to regulate the indiscriminate and unplanned development in flood plains. The basic concept is to regulate the land use in flood plain zoning in order to restrict the damage potential due to floods. The strategy for flood plain zoning should include the following aspects

Creation of flood zoning authority and its power

Surveys and delineation of flood plain area

Notification of limits of flood plains

Prohibition or restriction on the use of the flood plains

Compensation

Authority to remove constructions after prohibition (Sivakumar, 2015) 
The Rashtriya Barh Ayog and Central Water Commission (CWC) recommended that flood plain management measures should be undertaken and suitable management legislation enacted. This zoning is done by determining the locations and the extent of areas which are affected by floods of different magnitudes or frequencies and then to develop such areas where the damage is minimum in case of floods do occur. It is relevant both for unprotected as well as protected areas (Kaushik and Sharma, 2012).

Flood-plain zoning measures aim at demarcating zones or areas likely to be affected by floods of different magnitudes or frequencies and probability levels, and specify the types of permissible developments in these zones, so that whenever floods actually occur, the damage can be minimised, if not avoided. However, while all, in principle, generally endorse this approach, scant attention is given to it in actual practice, leading to increased flood damages. CWC has been continuously impressing upon the states for the need to take follow-up action to implement the flood plain zoning approach. A model draft bill for flood plain zoning legislation was also circulated by the Union Government in 1975 to all the States. There has been resistance on the part of the states to follow up the various aspects of flood plain management including possible legislation (Prasad and Mukherjee, 2014).

Lack of inflow forecasting systems for the reservoirs resulting in sudden release of large quantity of water

Reservoir inflow forecasting is crucial for appropriate reservoir management, especially in the flood season. Forecasting for this season must be sufficiently accurate and timely to allow dam managers to release water gradually for flood control in downstream areas (Amnatsan et al., 2018).
Accurate and reliable forecasting of reservoir inflow is necessary for efficient and effective water resources planning and management. The principal function of a reservoir is to regulate the natural stream flow by storing surplus water in the rainy season and releasing the stored water in the dry season to supplement the natural river flow. Reservoirs are the most effective means of changing temporal and spatial availability of water. Inflow to a reservoir is the basic input which is required to develop the optimal operation policy for a reservoir or a system of reservoirs. However, for a large number of Indian reservoirs, the reservoir inflow is not measured directly. Rather, reservoir level is measured at daily or sub-daily time step.

In many of the Indian reservoirs, the inflows into the reservoir are not directly measured in the upstream. Rather, continuous observations of reservoir levels at the dam site are made and reservoir inflows are computed indirectly using the reservoir water balance equation along with recorded outflows from the reservoir, precipitation inputs and evaporation losses from the reservoir water spread area. According to National Register of Large Dams 2002, there were about 4,050 completed large dams in India and another 475 were under construction. The number of completed large dams increased to 4,862 as of March 2016. As per Comptroller Audit General Report, 2017 Out of 4,862 large dams, Emergency Action Plans/Disaster Management Plans of only 349 large dams (seven per cent) were prepared [Report (2), 2017].

The recommendations of Comptroller Audit General in the report 2017 are worth implementing to overcome flood disaster concerning dams.

Ministry of Water resources (MoWR) may, in consultation with State Governments, devise a 
time bound action plan for preparation and implementation of Emergency Action Plans including preparation of inundation maps and hydrological studies for all the large dams in the country.

Ministry of Water resources (MoWR) may advise the State Governments to prepare Standard Operating Procedures for dams and carry out the prescribed pre and post monsoon inspection of the dams.

In conclusion the despite enhanced awareness on various disaster management related issues and mounting disaster induced losses disaster risk reduction is far from getting its due share of attention and resources, particularly in India. This is attributed to

departmental inertia, lacking political foresight and will, fragmented decision-making authority, lacking techno-legal regime and noncompliance of what exists,

lack of capacity building, unawareness of the mass, lacking risk assessment and communication, missing locally relevant data and examples, and

lack of objective and uniform disaster database

\section{The way forward}

The overcome the present gaps in addressing the flood disaster management the following strategies are recommended for disaster risk reduction,

Enhanced focus on mass awareness to ensure voluntary compliance and to do away with political apathy,

Comprehensive hazard, vulnerability and risk assessment and communication,

Enhanced investment on research and development related to disaster resilient technology and improvising traditional disaster risk reduction practices,

Enhanced investment on capacity building, Invoking disaster risk reduction compliant techno-legal regime and putting in place mechanism for its compliance,

NDMA and SDMA to be provided authority to issue binding guidelines,

Institutional mechanism for collecting precise and objective data relating to disaster induced losses (Mishra, 2001).

\section{References}

Adams III, T.E., 2019. Water Resources Forecasting Within the Indus River Basin: A Call for Comprehensive Modeling. In Indus River Basin (pp. 267-308). Elsevier.

Amnatsan, S., Yoshikawa, S. and Kanae, S., 2018.Improved forecasting of extreme monthly reservoir inflow using an analogue-based forecasting method: a case study of the sirikit dam in Thailand. Water, 10(11), p.1614.

Asian, D.R.C., 2002. Living with risk.A global review of disaster reduction initiatives.Preliminary version (No.INIS-XU--010).United Nations.

Cools, J., Innocenti, D. and O'Brien, S., 2016. Lessons from flood early warning systems. Environmental science \& policy, 58, pp.117-122.

Gangwar, S., 2013. Flood vulnerability in India: A remote sensing and GIS approach for warning, mitigation and management. International Journal of Environmental Science: Development and Monitoring, 4(2), pp.77-79.

Kaushik, A.D. and Sharma, V.K., 2012. Flood management in India. Indian Journal of Public Administration, 58(1), pp.119136.

Marco J.B..1994. Flood risk mapping. In: Rossi G., Harmancioğlu N., Yevjevich 
V. (eds) Coping with Floods. NATO ASI Series (Series E: Applied Sciences), vol 257. Springer, Dordrecht.https://doi.org/10.1007/97894-011-1098-3_20

Mishra, D.K., 2001. Living with Floods: People's Perspective. Economic and Political Weekly, pp.2756-2761

National Research Council, 2006. Completing the forecast: Characterizing and communicating uncertainty for better decisions using weather and climate forecasts. National Academies Press

Prasad, E. and Mukherjee, N., 2014. Situation Analysis on Floods and Flood Management. IUCN Bangladesh Country Office

Report (1). 2017 [book on-line.] CAG Report, No.10, Chapter 4. Available : https://www.cag.gov.in/uploads/downl oad_audit_report/2017/Chapter_4_Flood_Forecasting_of_Report_No.10of _2017_-Performance audit Union Government_Schemes_for_Flood_Con trol and Flood Forecasting Reports_of_Ministry_of_Water_Resou rces,_.pdf . [01 December 2020]

Report (2). 2017 [book on-line.] CAG Report, No.10, Chapter 5. Available : https://www.cag.gov.in/uploads/downl oad_audit_report/2017/Chapter_5__Other_Schemes_for_Flood_Control_o f_Report_No.10_of_2017__Performance_audit_Union_Governme nt_Schemes_for_Flood_Control_and_F lood_Forecasting_Reports_of_Ministry _of_Wat.pdf. [01 December 2020]

Roy, S.S., Mohapatra, M., Tyagi, A. and
BHOWMIK, S., 2019. A review of Now casting of convective weather over the Indian region. MAUSAM, 70(3), pp.465-484.

Sanyal, J. and Lu, X.X., 2003. Application of GIS in flood hazard mapping: a case study of Gangetic West Bengal, India. In Proceedings of map Asia conference, GIS development. net.

Singh, O. and Kumar, M., 2017. Flood occurrences, damages, and management challenges in India: a geographical perspective. Arabian Journal of Geosciences, 10(5), p.102.

Sivakumar, S.S., 2015. Flood mitigation strategies adopted in Sri Lanka a review. International Journal of Scientific and Engineering Research, 3(6).

Werner, M., Reggiani, P., De Roo, A.D., Bates, P. and Sprokkereef, E., 2005. Flood forecasting and warning at the river basin and at the European scale. Natural Hazards, 36(1-2), pp.25-42.

Wheater, H., Sorooshian, S. and Sharma, K.D. eds., 2007. Hydrological modelling in arid and semi-arid areas. Cambridge University Press.

WMO (2011) Manual on Flood Forecasting and Warning. World Meteorological Organization publication, WMONo.1072, Geneva, Switzerland. Available: https://www.wmo.int/ pages/prog/hwrp/publications/flood_for ecasting_warning/WMO\%201072_en.p df [02 May 2020]

\section{How to cite this article:}

Arun, L. and Senthilkumar, R. 2021. Gaps in Flood Disaster Management in India. Int.J.Curr.Microbiol.App.Sci. 10(01): 313-320. doi: https://doi.org/10.20546/ijcmas.2021.1001.039 